\title{
Associated Factors of Suboptimal Health Status Among Adolescents in China: A Cross-Sectional Study
}

\author{
Gehendra Mahara ${ }^{1} *$ \\ Jiazhi Liang ${ }^{2, *}$ \\ Zhirong Zhang ${ }^{3}$ \\ Qi Ge' \\ Jinxin Zhang'
}

'Department of Medical Statistics, School of Public Health, Sun Yat-Sen University, Guangzhou, 510080, People's Republic of China; ${ }^{2}$ Center for Disease Control and Prevention at Haizhu, Guangzhou, Guangdong, 510288, People's Republic of China; ${ }^{3}$ Nanhai District People's Hospital of Foshan City, Foshan, Guangdong,

People's Republic of China

*These authors contributed equally to this work
Correspondence: Jinxin Zhang

Department of Medical Statistics, School of Public Health, Sun Yat-Sen University, Guangzhou, 510080, People's Republic of China

Tel +86-20-87332453

Email zhjinx@mail.sysu.edu.cn
Purpose: Suboptimal health status (SHS) is a state between health and disease, has several adverse effects, although, its main underlying mechanism is still unclear. This study aimed to investigate SHS and its associated factors of adolescents.

Methods: A community-based cross-sectional study was conducted in the three different geographic locations of China (Shanxi, Guangzhou, and Tibet). A multidimensional subhealth questionnaire of adolescent (MSQA) is used to evaluate SHS. Independent twosample $\mathrm{K}-\mathrm{S}$ test was performed for the quantitative data as the non-parametric test, whereas Chi-square test method was applied to explore the difference of discrete variables data between groups. Then finally, multiple logistic regression analysis was applied to analyze the influential factors of SHS.

Results: Among 1461 respondents (between 15 and 18 years old), females proportion (56.47\%) was higher than males $(43.53 \%)$ where SHS was higher in Shanxi followed by Tibet and then Guangdong. The rural area, grade, lack of sleep time, home visit in a week, lack of exercise, a heavy burden of study, smoking, drinking, and fewer friends were the risk factors of SHS, while families living status, seeking help and extroversion were the protective factors. Conclusion: SHS is significantly associated with behavior and lifestyle-related factors. For comprehensively prevention and control of the SHS, it is urgently needed to reduce the risk factors and enhance the protective factors among adolescents.

Keywords: suboptimal health status, associated factors, high school students, Shanxi, Guangzhou, Tibet, China

\section{Introduction}

Health is the functional phenomenon of human-being. The condition of being sound in body, mind, spirit, and free from disease or pain is the meaning of health. ${ }^{1}$ In 1946, The World Health Organization (WHO) defined that "health is a state of complete physical, mental, and social well-being and, not merely the absence of disease or infirmity". ${ }^{2}$ Likewise, the suboptimal health or sub-health status, also known as suboptimal health status (SHS) ${ }^{3}$ is the physical state of people which is generally undiagnosed, ${ }^{4}$ however, some changes in psychological behavior or physical characteristics can observe, ${ }^{5}$ In fact, SHS is an intermediate state between health and disease condition. ${ }^{6}$ In this state, there are no organic lesions in the body, only characterized by persistent and recurrent fatigue, headaches, dizziness, anxiety, depression, as well as a series of symptoms including non-specific pain and sleep disorders. $^{4,6-10}$ 
Several studies suggested that SHS is as an intermediate state between health and disease, which is due to the physical, psychological, and social stress of an individual. ${ }^{11-15}$ Due to the physical and psychological behavior, the overall coordination of the body system become imbalance and dysfunction eg the nervous system, endocrine system, and immune system that lead to the decline of physiological, psychological, and social functions; however, the body has not yet reached the disease stage. ${ }^{6,8}$ Therefore, it is also regarded as a subclinical, reversible stage of chronic diseases ${ }^{3,6}$ Because, it has been known that SHS is a potential risk factor for chronic diseases such as type-II diabetes mellitus, cardiovascular and stroke etc. ${ }^{6,14,16} \mathrm{~A}$ number of studies have revealed that SHS is mainly influenced by lifestyle factors; ${ }^{11,12,17}$ these factors have a close relationship with psychological symptoms or behavior of individuals. ${ }^{15,18}$ Over time, with the rapid development of technology and changes in environment and lifestyles in China, the risk of SHS has been increasing consistently. ${ }^{14}$ Thus, SHS has been recognized as a public health challenge globally, including China. ${ }^{13,14,16,19}$

In addition, some scholars believe that the changes in the living environment, over workload, interpersonal relationship, lack of sleep time, excessive psychological stress, unbalanced diet, and an inappropriate exercise may lead to the formation of SHS. ${ }^{20,21}$ Likewise, a study reported that socio-cultural factors are the key determinants of SHS of students. ${ }^{12}$ Furthermore, a survey conducted by Xie et al among the middle school students' found that school environmental and psychological factors, life events, lifestyle, social, natural, and family factors are the risk factors for SHS. ${ }^{22}$ Similarly, Tu et al, ${ }^{23}$ reported that the causes of SHS among teenagers/adolescence are excessive academic burden, family stress, noise, sleep time, less exercise, social and living environmental impacts, lifestyle, and physiological factors. Similarly, Cao et $\mathrm{al}^{24}$ found that drug abuse, eating habits, weight loss, exercise, internal injury, suicide, and internet addiction are the major risk factor for the psychological SHS in middle school students. To date, there has not been found the exact cause of the SHS. It has believed that SHS occurs due to different associated factors, although, its underlying mechanism is remaining unclear.

The prevalence of SHS is varied among different age groups, gender, geographic region, and occupations. ${ }^{20,25,26}$ It has found $51.2 \%$ in college students, whereas, $69.46 \%{ }^{21}$ in adults and that seems to be increasing with age ${ }^{21}$ and high prevalence noted in rural area compared to urban settings. ${ }^{4}$ Likewise, the prevalence of SHS had seen higher in women compared to men, which looks the same status from children to adult population., ${ }^{4,11,20,27}$ Similarly, $74.21 \%$ prevalence rate found among nurses in China. ${ }^{26}$ The prevalence rate of SHS found $65 \% .02$ in youths, $71.08 \%$ in middle-aged adults and $72.48 \%$ in older adults. Additionally, SHS was found statistically significant among different profession, such as blue-collar workers had higher (73.71\%) compared to white-collar workers, and SHS decreased with increased educational level. ${ }^{20}$ The SHS prevalence rate was found high in widowed then single or married people. ${ }^{20}$ Notably, almost all studies revealed that lifestyle behaviors are the main associated factors of SHS. ${ }^{4,14,26,28}$

Previous studies have quantified that SHS is a public health problem in China. However, studies regarding SHS and its associated factors of high school students in the study settings are limited. Therefore, this study aimed to examine the SHS of High School Students in Guangzhou, Shanxi, and Tibet, and we also quantify the associated factors of SHS among participants.

\section{Materials and Methods}

A community based, cross-sectional study conducted in China to investigate the SHS and its associated factors among high school students. We first selected three regions in China by means of convenient sampling (central areas in the central part: Shanxi Yuci, developed coastal areas: Guangzhou, Guangdong, remote areas in the west: Linzhi, Tibet). ${ }^{29}$ We selected key high school and ordinary high school. In each school, two classes from each grade student (High-I, II \& III) were randomly selected by a stratified cluster sampling method. The sample size of this survey was calculated based on the National Normal Model Survey, where the detection rate of physical SHS and psychological SHS of high school students in China were (34.6-53.9\%), ${ }^{30}$ the relative error was not more than $20 \%$, and the confidence level reached $95 \%$. The requirements are calculated by substituting the formula to obtain a minimum sample size of 182 in each region and 546 in three regions. In this survey, a total of 1472 high school students were surveyed. Excluded the questionnaires having missing items (leakage rate $>10 \%$ ), 1461 students were effectively surveyed with a $99.25 \%$ effective rate, which could meet the sample size requirements for this study. 


\section{SHS Evaluation}

Since our study was based on the Chinese population, we used the "Multidimensional sub-health Questionnaire of Adolescents (MSQA)" to know the SHS of respondents. ${ }^{30}$ MSQA is an effective, sensitive, and validated SHS tool for adolescents. ${ }^{31}$ The adolescent's degree of SHS was evaluated by the level of physiological SHS and psychological SHS. MSQA questionnaire has 71 items; each item has 6 levels. The score of SHS is 1 to 6 points. The higher score of the point indicates the more serious SHS. ${ }^{30}$ (Appendix 1)

\section{Associated Factors of SHS}

The researcher from other countries has been using chronic fatigue as a syndrome in the research content, ${ }^{32}$ while its definition is different from the SHS. Physical SHS explore the human's health history or illness status whereas psychological SHS mainly related with mental conditions, such as depression, anxiety, or chronic fatigue including mental health condition. ${ }^{33}$ Therefore, this study combined the actual situation of Chinese students based on the Chinese scholars' studies and the current knowledge of sub-health theories regarding factors affecting the SHS. ${ }^{30,34}$ The factors affecting SHS are divided into selffactors (Gender, ethnicity, Body Mass Index (BMI), grade, whether they are only children, time spent on school, sleep time, learning burden, frequency on exercise, internet surfing, smoking habit, alcohol consumption, diet, seeking help, personality, etc), family factors (family location, family structure, parental expectations, parental education, the annual income of family, level), school factors (key high school and ordinary high school), and other factors (student source, interpersonal relationship) etc (Table S1).

\section{Data Collection}

The pre-test was conducted prior to the formal investigation. The first grade of an ordinary high school in Guangzhou was selected by means of convenient sampling for the pre-test. The information associated with survey questions and calculated scales were revised after getting feedback from the pre-test and then finalized the questionnaire for the final study.

Students were filled with information anonymously by means of centralized filling, independent answering, onthe-spot recycling, and on-the-spot investigation. At the spot, the local education authorities and their subordinate schools co-operated closely. Investigators collect all filled questionnaires after the survey was completed. The interview/survey was excluded from those participants who declined to participate in the survey. The questionnaire was finished by each respondent within $20 \mathrm{~min}$. All information of the respondents was kept strictly confidential.

\section{Ethical Approval}

Ethical approval was approved (approval No.2018, 50) by the Ethics Committee of the School of Public Health, Sun Yat-Sen University, Guangzhou, China, and the committee waived the requirement for parental consent, because the participants were middle school students and the selected variables in the questionnaire were only about the daily activities of the students. This study was conducted in accordance with the Declaration of Helsinki. The schools were consulted, and a letter of permission to conduct the study was signed by the person in charge of academic affairs on behalf of students. The participants were informed regarding the purpose of the questionnaire, and they were made aware that completing the questionnaire was voluntary. Completing the questionnaire was deemed consent.

\section{Statistical Analysis}

Epidata-3.1 software was used to record the database. Normality distributed quantitative data were displayed as mean and standard deviations, where non-normally distributed data were represented as medians and quartiles $\left(\mathrm{P}_{25} \mathrm{P}_{75}\right)$. Qualitative data were presented as a rate or percentage. A Pearson chi-square $\left(\chi^{2}\right)$ test was applied to compare between groups. The influencing factor of SHS was estimated using logistic regression analysis for multivariate analysis, by adjusted Odds ratios (AOR) and 95\% confidence interval (CI). All statistical analyses carried out using SPSS 23.0 software. All reported $\mathrm{P}$ values were two-sided, and $\mathrm{P}<0.05$ was considered statistically significant.

\section{Results}

\section{Basic Characteristics of Respondents}

A total of 1472 respondent, 11 participants were excluded due to missing items or information in the questionnaire. Finally, 1461 high school students were enrolled in this survey. There were $43.53 \%$ (636) male and 56.47\% (825) female with the mean age of $17.30 \pm 1.27$ years, and participants from Shanxi 31.76\% (464), Guangdong 33.61\% (491), and Tibet 34.63\% (506) (Table S2). The result showed 
that tiredness and fatigue were high (11.98\%) observe in physical SHS, while challenging to study at home $(19.10 \%)$ in psychological SHS, among other symptoms, detail about the symptoms of both groups is displayed in Table 1 .

The survey results showed that there were significant differences in the physical SHS and psychological SHS along with different detection rates among the high school students in the three regions. Psychological SHS was higher in Shanxi (20.69\%) followed by Tibet (18.77\%) and Guangzhou (13.03\%) among surveyed populations (Table 2).

\section{SHS Detection Score and Rate by Gender}

The results of this study showed that the detection rate of physical SHS symptoms and the Psychological SHS of females was higher than that of males, which is the statistically significant (Table S3 and 4).

Table I Symptoms of SHS and Mental SHS

\begin{tabular}{|c|c|c|c|c|c|}
\hline \multicolumn{3}{|c|}{ Sub-Health Symptoms } & \multicolumn{3}{|c|}{ Psychological Sub-Health Symptoms } \\
\hline Symptoms & Respondent & $\begin{array}{c}\text { Detection Rate } \\
\text { (\%) }\end{array}$ & Symptoms & $\begin{array}{c}\text { Respondent } \\
\text { No. }\end{array}$ & $\begin{array}{c}\text { Detection Rate } \\
\text { (\%) }\end{array}$ \\
\hline Tiredness, Fatigue & 175 & 11.98 & It's hard to study at home & 279 & 19.10 \\
\hline Dry eyes & 149 & 10.20 & Concentration on study & 233 & 15.95 \\
\hline Nasal congestion & 128 & 8.76 & Unwilling to talk to others & 215 & 14.72 \\
\hline I cannot sleep well. & 121 & 8.28 & I do not want to see help & 209 & $0 \mid 4.31$ \\
\hline Drink more and eat more & 120 & 8.21 & Hesitate & 207 & 014.17 \\
\hline Wake up too early & 111,115 & 7.87 & $\begin{array}{l}\text { Difficult to remember learning } \\
\text { content }\end{array}$ & 205 & 014.03 \\
\hline Difficulty falling asleep & 112 & 7.67 & Unnecessary thoughts & 203 & 013.89 \\
\hline Sore eyes & 102 & 6.98 & Irritable & 200 & 013.69 \\
\hline Weak limbs & 99 & 6.78 & $\begin{array}{l}\text { No hope in the future } \\
\text { Do not trust others } \\
\text { Worried about the teacher asking } \\
\text { questions } \\
\text { Feel difficulty of learning }\end{array}$ & $\begin{array}{l}170 \\
165 \\
164 \\
163\end{array}$ & $\begin{array}{l}011.64 \\
011.29 \\
011.23 \\
011.61\end{array}$ \\
\hline
\end{tabular}

Table 2 Detection of SHS in Different Regions

\begin{tabular}{|l|c|c|c|c|c|}
\hline \multirow{2}{*}{ Area } & \multirow{2}{*}{$\begin{array}{c}\text { Number of } \\
\text { Respondents }\end{array}$} & \multicolumn{2}{|c|}{ Sub-Health } & \multicolumn{2}{c|}{ Psychological SHS } \\
\cline { 3 - 6 } & & $\begin{array}{c}\text { Symptom Check- } \\
\text { Out }\end{array}$ & Status Check-Out & $\begin{array}{c}\text { Symptom Check- } \\
\text { Out }\end{array}$ & Status Check-Out \\
\hline Shanxi & 464 & $207(44.61)$ & $115(24.78)$ & $242(52.16)$ & $96(20.69)$ \\
\hline Guangdong & 491 & $188(38.29)$ & $88(17.93)$ & $203(41.34)$ & $64(13.03)$ \\
\hline Tibet & 506 & $199(39.33)$ & $106(20.95)$ & $229(45.26)$ & $95(18.77)$ \\
\hline Chi test & $\chi^{2}$ & 4.520 & 6.754 & 11.459 & 10.640 \\
\hline Comparison & $P$ & 0.104 & $\mathbf{0 . 0 3 4}$ & $\mathbf{0 . 0 0 3}$ & $\mathbf{0 . 0 0 5}$ \\
\hline
\end{tabular}

Notes: ${ }^{a}$ Is compared with Shanxi, and the difference is statistically significant; ${ }^{b}$ is compared with Guangdong, and the difference is statistically significant. Symptom checkedout to those participants who were assumed to have either physical or psychological symptoms. Bold formatting indicates the statistically significant $<0.05$. 


\section{Multiple Logistic Regression Analysis of Influencing Factors with SHS and Psychological SHS}

In order to know the comprehensive effect of the factors affecting the SHS, a stepwise multi-factor unconditional logistic regression analysis was carried out. The result of this analysis showed that the region, lack of sleep time, heavy learning burden, lack of exercise, drinking alcohol, lack of frequent home visit, and eating habit were the statistically significant associated risk factors of SHS, while an hour of daily internet access was found to be a protective factor for the SHS (Table 2).

Similarly, the results of logistic regression analysis (after adjusted the covariate) found that the region (rural), grade of class, lack of sleep time, heavy learning burden, less than one time per week home visit, lack of exercise, smoking, drinking, and fewer friends were the risk factors for psychological SHS, while females (gender), family, township, seeking help, and extroversion were the protective factors for the occurrence of psychological SHS (Table 3).

\section{Discussion}

This study aimed to distinguish the SHS and its associated influential factors among high school students in three geographic regions of China. The study found that the overall detection rate of SHS was $55.10 \%$, where the detection rates of physical SHS and Psychological SHS were $25.80 \%$ and $46.13 \%$. Compared with the previous studies among high school students by using MSQA scale, ${ }^{34,35}$ their detection rates of SHS symptoms ranged from $27.00 \%$ to $75.30 \%$, and the detection rate was $12.40 \%$ in the range of $41.12 \%$, except for the symptoms of the physical SHS which was slightly lower. The results of the above surveys are almost the same as the results of our study, which indicates that the SHS occurrence stages among the high school students were ubiquitous. The detection rate of physical and psychological SHS was lower than the national level (physical SHS-34.60\%, Psychological SHS-46.84\%, and overall detection rate at the national level SHS-53.92\%). ${ }^{30}$ An earlier study conducted in our study area found that the overall SHS detection rate in urban high school students in Guangzhou City was $38.53 \% .{ }^{35}$ The detection rate difference might be due to the difference between the survey method and the measurement scale.
Several SHS measuring tools have been established. Additional, a comprehensive and validated tool for SHS stands the Suboptimal Health Status Questionnaire (SHSQ-25), ${ }^{3}$ predominantly targeted at the Physiological and Psychological status of people, has been widely applying at the national or international level in different ethnic groups (Asian, African, and Caucasians), which is also a new mechanism to enables people for early intervention in terms of Predictive, Preventive and Personalized Medicine (PPPM) ${ }^{36-38}$ Similarly, MSQA scale evaluates the SHS of adolescents, which is a valid and approved tool in China, which is formulated by Tao et al. ${ }^{30}$ The testretest reliability, Cronbach alpha $(\alpha)$ coefficient, and splithalf reliability coefficient were $0.87,0.96$, and 0.94 , respectively, which was conducted among 7104 middle school students. ${ }^{31}$ The study of Chao confirmed that MSQA is a credible, effective, and sensitive SHS tool for adolescents. ${ }^{31}$ Therefore, to assess the SHS of adolescents, MSQA is a suitable measuring scale; thus, we applied in our study.

The study result showed that the geographical region, rural area, lack of sleep time, heavy learning burden, drinking alcohol, lack of frequent home visit, and eating habit were significant risk factors for SHS, similarly the region (rural), the grade of class, lack of sleep time, heavy learning burden, personal behaviour, less than one time per week home visit, lack of exercise, smoking, and drinking, were risk factors for psychological SHS. Interestingly, only an hour of daily internet access was found to be a protective factor for physical SHS, whereas, seeking help, and extroversion were the protective factors for the psychological SHS. Consistently, Zhao ${ }^{39}$ and Hou et al, ${ }^{15}$ reported that the main physiological problems of middle school students are fatigue, dizziness, gastrointestinal discomfort, and poor sleep tendency. Proper and active exercise, a balanced diet, avoid alcohol, and tobacco habit is the best way to overcome from SHS.

Notably, this study found that surfing the internet for no more than an hour in a day was a protecting factor for SHS for high school students. This finding is supported by a study that long-term internet access, high frequency of internet access, and internet addiction are the significant risk factors for SHS, ${ }^{40}$ which is consistent with our study. The short-term internet access can alleviate the student's stressful learning pressure to a certain extent so that their life rhythm can be slowed down.

An earlier study ${ }^{40}$ suggested that, in terms of gender, females have their own physiological characteristics, 
Table 3 A Multi-Factor Unconditional Logistic Regression Model of Associated Factors of Psychological SHS

\begin{tabular}{|c|c|c|c|c|c|c|}
\hline \multirow[t]{2}{*}{ Variables } & \multirow[t]{2}{*}{ Number (\%) } & \multirow[t]{2}{*}{ OR } & \multirow[t]{2}{*}{ AOR } & \multicolumn{2}{|c|}{$95 \% \mathrm{Cl}$} & \multirow[t]{2}{*}{ P-value } \\
\hline & & & & Lower & Upper & \\
\hline \multicolumn{7}{|l|}{ Area } \\
\hline Guangzhou & $49 I(33.6 I)$ & - & - & - & - & 0.009 \\
\hline Shanxi & $464(31.76)$ & 1.908 & 1.887 & 1.239 & 2.874 & 0.003 \\
\hline Tibet & $506(34.63)$ & 1.239 & 1.285 & 0.699 & 2.399 & 0.430 \\
\hline \multicolumn{7}{|l|}{ Gender } \\
\hline Female & $825(56.47)$ & 0.583 & 0.679 & 0.470 & 0.980 & 0.039 \\
\hline \multicolumn{7}{|l|}{ Grade } \\
\hline High-I & $521(35.67)$ & - & - & - & - & 0.029 \\
\hline High-II & $536(36.68)$ & 1.811 & 1.728 & 1.097 & 2.720 & 0.018 \\
\hline High-III & $404(27.65)$ & 1.738 & 1.752 & 1.128 & 2.723 & 0.013 \\
\hline \multicolumn{7}{|l|}{ Residence } \\
\hline Urban & $465(31.82)$ & - & - & - & - & 0.037 \\
\hline Rural & 77(5.27) & 0.402 & 0.588 & 0.351 & 0.983 & 0.043 \\
\hline Township & | 38(9.45) & 0.856 & 1.141 & $0.54 I$ & 2.406 & 0.730 \\
\hline County & 69(4.74) & 1.391 & 1.450 & 0.772 & 2.723 & 0.248 \\
\hline Suburb & $712(48.74)$ & 0.709 & 0.802 & 0.350 & $\mathrm{I} .837$ & 0.602 \\
\hline \multicolumn{7}{|l|}{ Home visits } \\
\hline No visit & $238(16.29)$ & - & - & - & - & 0.013 \\
\hline 3 or mode days & $205(14.03)$ & 3.155 & 2.478 & 1.295 & 4.745 & 0.006 \\
\hline I-2 visit & $1018(69.68)$ & 1.759 & 1.410 & 0.757 & 2.627 & 0.279 \\
\hline \multicolumn{7}{|l|}{ Sleep time } \\
\hline$>8$ hours & $158(|0.8|)$ & - & - & - & - & 0.002 \\
\hline$<6$ hours & $1234(84.46)$ & 11.417 & 9.459 & 2.035 & 43.971 & 0.004 \\
\hline $6-8$ hours & 69(4.72) & 6.715 & 5.077 & 1.148 & 22.459 & 0.032 \\
\hline \multicolumn{7}{|l|}{ Learning burden } \\
\hline Very light & $307(21.01)$ & - & - & - & - & $<0.001$ \\
\hline Light & $556(38.06)$ & 0.379 & 0.232 & 0.018 & 2.965 & 0.261 \\
\hline General & $536(36.69)$ & 2.074 & 2.084 & 0.828 & 5.244 & 0.119 \\
\hline Heavy & $40(2.74)$ & 2.289 & 2.427 & 1.566 & 3.761 & $<0.001$ \\
\hline Very heavy & $22(I .5 I)$ & 0.919 & 0.990 & 0.674 & 1.454 & 0.960 \\
\hline \multicolumn{7}{|c|}{ Frequency of movement } \\
\hline $2-3$ times & $329(22.52)$ & - & - & - & - & $<0.001$ \\
\hline 3 or more times & $575(39.36)$ & 2.507 & 2.472 & 1.629 & 3.750 & $<0.001$ \\
\hline No movement & $557(38.12)$ & 0.933 & 0.914 & 0.611 & 1.369 & 0.663 \\
\hline Smoking & $105(7.19)$ & 2.202 & 2.138 & 1.170 & 3.906 & 0.013 \\
\hline Drinking & $246(16.83)$ & 1.969 & 2.344 & 1.558 & 3.526 & $<0.001$ \\
\hline Seeking help & $1329(90.96)$ & 0.386 & 0.378 & 0.227 & 0.630 & $<0.001$ \\
\hline \multicolumn{7}{|c|}{ Interpersonal communication } \\
\hline$>6$ and above & $36(2.46)$ & - & - & - & - & $<0.001$ \\
\hline No. & $367(25.12)$ & 14.232 & 10.324 & 3.902 & 27.314 & $<0.001$ \\
\hline $\mathrm{I}-2$ & $629(43.05)$ & 2.701 & 2.543 & 1.580 & 4.092 & $<0.001$ \\
\hline $3-5$ & $429(29.36)$ & 1.842 & 1.839 & 1.196 & 2.828 & 0.006 \\
\hline Personal Behaviour & $1040(71.18)$ & 0.576 & 0.647 & 0.456 & 0.917 & 0.014 \\
\hline
\end{tabular}

Note: $<0.05$ with bold is assumed as significant. 
those are more sensitive, delicate as well as the more complex during the physical and psychological changes of adolescence period, thus difficult to guide them at this period, which makes females more likely to have SHS. Our study also found that SHS was high among female students, which is also supported by the study of Cao et $\mathrm{al}^{24}$ and Yao et al. ${ }^{18}$ The number of friends or pair groups is a very important influencing factor for the psychological SHS of young students. The results of previous studies $^{40,41}$ displayed that the relationship with classmates, the number of friends, misunderstanding between friends of the middle school students had more SHS, which are closely similar to our study. Interpersonal relationships and the number of friends showed a positive relationship with students; in this stage, students are more willing to share their inner world with others, resulting in they can exchange social support. When they encounter difficulties, they can flexibly use the surrounding interpersonal relationships to enhance their confidence, strength, and overcome.

Similarly, poor lifestyle behaviors such as; smoking and drinking are the main influencing factors of Psychological SHS. ${ }^{11}$ A study of Lolokote et al reported that significant relationship between SHS and the use of tobacco and alcohol in the college students. ${ }^{12}$ Our study also found that smoking and drinking are risk factors for SHS of high school students. A study to investigate the risky health behavior of middle school students reported ${ }^{41}$ that smoking behaviors among adolescent students are often accompanied by drinking behavior, by which they show obvious psychological issues such as depression, anxiety, nervousness, and temper, because it has well known that SHS is highly influenced by unhealthy lifestyle. ${ }^{42}$

This survey analyzed the status of SHS among high school students in three economic, geographical, cultural, and environmentally different regions of China. It has known that China has a socio-economic and topographically diverse landscape, due to that the healthcare facilities are unevenly distributed. ${ }^{43}$ Likewise, there are significant regional diversities explored in Cardio Vascular Disease (CVD), where undesirable features also seen for example; inequalities in healthcare services including nutritional status among different socioeconomic status and ethnic groups. ${ }^{44}$ The SHS has also found an independent potential risk factors for type 2 diabetes mellitus, ${ }^{10,16,45}$ CVD metrics, including different Immunoglobulin Glycosylation, ${ }^{46}$ intestinal microbiota, ${ }^{9}$ BMI indicators, and blood pressure and other cardio metabolic risk measures. ${ }^{46}$
The associated factors of SHS, and results provided a holistic picture of both subjective and objective health measures from the perspective of PPPM. ${ }^{15}$ PPPM is a new comprehensive approach in the healthcare sector that allows predicting individual predisposition before the onset of the disease, also provide targeted preventive methods, and create personalized treatment procedures tailored to the person. ${ }^{37} \mathrm{In}$ recent days, treatment for the non-communicable disease (NCD) are executed after disease onset, which is a very much slow approach from the PPPM perspective. ${ }^{15}$ Therefore, timely diagnosis and management of SHS in the society is the holistic approach in terms of PPPM.

However, some limitations must be considered when interpreting the findings of this study. This study used a prospective questionnaire survey method, which is difficult to avoid bias and errors caused by differences in understanding an ability among students from different regions or ethnic groups. This was a cross-sectional survey, which did not allow us to assess accurate causality between psychological symptoms and physical SHS. And data was obtained by the self-rating questionnaire, which might have led to information bias. The participants were selected by a convenient sampling method, which leaves the potential for selection bias, and limited generalizability, the relevancy of results to other populations. We tried to fit the GLM-log binomial model, but could not be able to include all variables it might be due to the data quality, therefore the result of GLM$\log$ binomial is not reasonable to establish and generalize the result. Thus, we interpreted the result of logistic regression model for this study. It is recommended for the future study with the quality of data for robust result.

\section{Conclusion}

This study evaluated the SHS of high school students in three regions in China, where SHS was found high in Shanxi, followed by Tibet and Guangzhou. The SHS among females was high than that of males. Rural areas, grades of class, lack of sleep time, heavy study burden, low number of home visits per week, lack of exercise, smoking, drinking, and fewer friends were risk factors for SHS, while, family in townships, seeking help, extroversion person were a protective factor for the occurrence of SHS. Through the comprehensive prevention and control measures of the school and family of the student, promote students to develop good habits, promptly guide various psychological problems and adjust social adaptability, timely detect and treat the sub-health symptoms that have 
emerged, and effectively prevent and control the student's health.

\section{Acknowledgment}

The authors thank the Ministry of Science and Technology, National Natural Science Foundation of China and, Natural Science Foundation of Guangdong Province, China, China for providing us the fund and technical support for this study.

\section{Funding}

This work was supported by the National Natural Science Foundation of China (NSFC, 81773545); and the Natural Science Foundation of Guangdong Province, China (2016A030313365). The funders had no role in study design, data collection and analysis, decision to publish, or preparation of the manuscript.

\section{Disclosure}

The authors declare that they have no conflicts of interests.

\section{References}

1. Merriam-Webster. Definition of HEALTH. Dictionary. Available from: https://www.merriam-webster.com/dictionary/health. Accessed March 21, 2019.

2. World Health Organization. Preamble to the constitution of the World Health Organization as adopted by the international health conference. New York: official records of the World Health Organization, No.2, p.100, and entered into force on 7 April 1948; 1946. Available from: https://www.who.int/about/who-we-are/constitution. WHO Definition of Health.

3. Yan Y-X, Liu Y-Q, Li M, et al. Development and evaluation of a questionnaire for measuring suboptimal health status in urban Chinese. $J$ Epidemiol. 2009;19(6):333-341. doi:10.2188/jea. JE20080086

4. Xue Y, Huang Z, Liu G, et al. Association analysis of suboptimal health status: a Cross-Sectional Study in China. PeerJ. 2020;8: e10508. doi:10.7717/peerj. 10508

5. Li G, Xie F, Yan S, et al. Subhealth: definition, criteria for diagnosis and potential prevalence in the central region of China. BMC Public Health. 2013;13(1):446. doi:10.1186/1471-2458-13-446

6. Wang W, Yan Y. Suboptimal health: a new health dimension for translational medicine. Clin Transl Med. 2012;1(1):28. doi:10.1186/ 2001-1326-1-28

7. Tavel ME. Somatic symptom disorders without known physical causes: one disease with many names? Am J Med. 2015;128 (10):1054-1058. doi:10.1016/j.amjmed.2015.04.041

8. Wang W, Zhou M, Wang L. The concept and characteristics of sub-health and its relationship with chronic fatigue syndrome. Chin J Behav Med Brain Sci. 2010;19(1).

9. Sun Q, Xu X, Zhang J, et al. Association of suboptimal health status with intestinal microbiota in Chinese youths. $J$ Cell Mol Med. 2020;24(2):1837-1847. doi:10.1111/jcmm.14880

10. Ge S, Xu X, Zhang J, et al. Suboptimal health status as an independent risk factor for type 2 diabetes mellitus in a community-based cohort: the China Suboptimal Health Cohort Study. EPMA J. 2019;10 (1):65-72. doi:10.1007/s13167-019-0159-9
11. Ma C, Xu W, Zhou L, Ma S, Wang Y. Association between lifestyle factors and suboptimal health status among Chinese college freshmen: a Cross-Sectional Study. BMC Public Health. 2018;18(1). doi:10.1186/s12889-017-5002-4

12. Lolokote S, Hidru TH, Li X. Do socio-cultural factors influence college students' self-rated health status and health-promoting lifestyles? A Cross-Sectional Multicenter Study in Dalian, China. BMC Public Health. 2017;17(1):478. doi:10.1186/s12889-017-4411-8

13. Wang Y, Ge S, Yan Y, et al. China suboptimal health cohort study: rationale, design and baseline characteristics. J Transl Med. 2016;14 (1):291. doi:10.1186/s12967-016-1046-y

14. Wang Y, Liu X, Qiu J, et al. Association between ideal cardiovascular health metrics and suboptimal health status in Chinese population. Sci Rep. 2017;7(1):14975. doi:10.1038/s41598-017-15101-5

15. Hou H, Feng X, Li Y, et al. Suboptimal health status and psychological symptoms among Chinese college students: a perspective of predictive, preventive and personalised health. EPMA J. 2018;9 (4):367-377. doi:10.1007/s13167-018-0148-4

16. Adua E, Roberts P, Wang W. Incorporation of suboptimal health status as a potential risk assessment for type II diabetes mellitus: a Case-Control Study in a Ghanaian population. EPMA J. 2017;8 (4):345-355. doi:10.1007/s13167-017-0119-1

17. Bi J, Huang Y, Xiao Y, et al. Association of lifestyle factors and suboptimal health status: a cross-sectional study of Chinese students. BMJ Open. 2014;4(6):e05156-e005156. doi:10.1136/bmjopen2014-005156

18. Yao Y, Wang L, Chen Y, et al. Correlation analysis of anxiety status and sub-health status among students of 13-26 years old. Int J Clin Exp Med. 2015;8(6):9810-9814.

19. Alzain MA, Asweto CO, Zhang J, et al. Telomere length and accelerated biological aging in the china suboptimal health cohort: a CaseControl Study. OMICS. 2017;21(6):333-339. doi:10.1089/omi.2017. 0050

20. Xu T, Zhu G, Han S. Prevalence of suboptimal health status and the relationships between suboptimal health status and lifestyle factors among Chinese adults using a multi-level generalized estimating equation model. Int J Environ Res Public Health. 2020;17(3):763. doi:10.3390/ijerph17030763

21. Xu T, Liu J, Zhu G, Han S. Prevalence and associated lifestyle factors of suboptimal health status among Chinese children using a multi-level model. Int J Environ Res Public Health. 2020;17(5). doi:10.3390/ijerph17051497

22. Xie W, Wu Y, Wang A. Analysis of related factors of sub-health status of middle school students. Chin Adv Health Care. 2000;14 (10):53-54.

23. Tu C, Xing C, He B. Analysis of the status of adolescents' sub-health in Shaoxing and its influencing factors. J Sch Health. 2010;31 (12):1409-1412.

24. Cao H, Cui W, Zhao H. Epidemiological analysis of the relationship between life events and sub-health in 1483 middle school students. J Med Sci Yanbian Univ. 2013;1:34-37.

25. Anto EO, Roberts P, Coall D, et al. Integration of suboptimal health status evaluation as a criterion for prediction of preeclampsia is strongly recommended for healthcare management in pregnancy: a Prospective Cohort Study in a Ghanaian population. EPMA J. 2019;10(3):211-226. doi:10.1007/s13167-019-00183-0

26. Zhu J, Ying W, Zhang L, et al. Psychological symptoms in Chinese nurses may be associated with predisposition to chronic disease: a Cross-Sectional Study of Suboptimal Health Status. EPMA J. 2020;11(4):551-563. doi:10.1007/s13167-020-00225-y

27. Jiang D, Yao R, Yuan C, Hu L. Correlation analysis of sub-health status and health-related risk behaviors in college students. Nan Fang Yi Ke Da Xue Xue Bao. 2011;31(1):61-64.

28. Chen J-Y, Yu K-Q, Sun X-M, et al. Effect of health-promoting lifestyle on outcomes of suboptimal health status]. Nan Fang Yi Ke Da Хие Хие Вао. 2016;37(2):184-191. 
29. National Bureau of Statistics of China. Available from: http://www. stats.gov.cn/english/. Accessed October 10, 2018.

30. Tao F, Hu C, Sun Y, Hao J. The development and application of multidimensional sub-health questionnaire of adolescents (MSQA). Chin J Dis Control Prev. 2008;12:309-314.

31. Xing C, Tao F, Yuan C, et al. Evaluation of reliability and validity of the multidimensional sub-health questionnaire of Adolescents. Chin J Public Health. 2008;24:1031-1033.

32. Crawley E, Sterne JAC. Association between school absence and physical function in paediatric chronic fatigue syndrome/myalgic encephalopathy. Arch Dis Child. 2009;94(10):752. doi:10.1136/ adc. 2008.143537

33. Sun N, Wang L. The relevance of mental and physical sub-health status. Int $J$ Cardiol. 2011;152:S93-S94. doi:10.1016/j. ijcard.2011.08.778

34. Fang Q, Wang H, Li L. Analysis of sub-health status and risk behaviors of middle school students in a county of Chongqing. Chin Public Health. 2013;1:94-96.

35. Liu C, Li Z, Ma G. Investigation and analysis of sub-health status of middle school students in Guangzhou City. J Guangdong Coll Pharm. 2004;6:676-677.

36. Kupaev V, Borisov O, Marutina E, Yan Y-X, Wang W. Integration of suboptimal health status and endothelial dysfunction as a new aspect for risk evaluation of cardiovascular disease. EPMA J. 2016;7(1):19. doi:10.1186/s13167-016-0068-0

37. Wang W, Russell A, Yan Y. Traditional Chinese medicine and new concepts of predictive, preventive and personalized medicine in diagnosis and treatment of suboptimal health. EPMA J. 2014;5(1):4. doi:10.1186/1878-5085-5-4

38. Yan Y-X, Wu L-J, Xiao H-B, Wang S, Dong J, Wang W. Latent class analysis to evaluate performance of plasma cortisol, plasma catecholamines, and SHSQ-25 for early recognition of suboptimal health status. EPMA J. 2018;9(3):299-305. doi:10.1007/s13167-018-0144-8
39. Zhao S, Sun C, Wang D. Analysis of the status of body subhealth in 1324 middle school students. J Qiqihar Med Coll. 2009;30 (17):2169-2171.

40. Ren L, Li J. Analysis of sub-health status and related factors of a high school student in Weinan City. Chin Sci Technol Inform. 2013;5:78-79.

41. Jiang $\mathrm{C}, \mathrm{Fu} \mathrm{X}$, Yang $\mathrm{H}$. Investigation on health risk behavior of middle school students in urban district of Hangzhou. J Sch Health. 2006;27(12):1037-1038.

42. Chen J, Xiang H, Jiang P, et al. The role of healthy lifestyle in the implementation of regressing suboptimal health status among college students in China: a Nested Case-Control Study. Int J Environ Res Public Health. 2017;14(3):240. doi:10.3390/ijerph14030240

43. Zhang M, Shi Y, Shi O, et al. Geographical variations in cardiovascular health in China: a nationwide population-based survey of 74,726 adults. Lancet Public Health. 2020;3:100033. doi:10.1016/j. lanwpc.2020.100033

44. Wang W. Cardiovascular health in China: low level vs high diversity. Lancet Public Health. 2020;3:100038. doi:10.1016/j. lanwpc.2020.100038

45. Adua E, Roberts P, Sakyi SA, et al. Profiling of cardio-metabolic risk factors and medication utilisation among type II diabetes patients in Ghana: a Prospective Cohort Study. Clin Transl Med. 2017;6(1). doi:10.1186/s40169-017-0162-5

46. Liu D, Li Q, Dong J, et al. The association between normal BMI with central adiposity and proinflammatory potential immunoglobulin G N-glycosylation. Diabetes Metab Syndr Obes. 2019;12:2373-2385. doi:10.2147/DMSO.S216318
Journal of Multidisciplinary Healthcare

\section{Publish your work in this journal}

The Journal of Multidisciplinary Healthcare is an international, peerreviewed open-access journal that aims to represent and publish research in healthcare areas delivered by practitioners of different disciplines. This includes studies and reviews conducted by multidisciplinary teams as well as research which evaluates the results or conduct of such teams or healthcare processes in general. The journal covers a very wide range of areas and welcomes submissions from practitioners at all levels, from all over the world. The manuscript management system is completely online and includes a very quick and fair peer-review system. Visit http://www.dovepress.com/testimonials. php to read real quotes from published authors. 